\title{
COVID-19 fake news diffusion across Latin America
}

\author{
Wilson Ceron $^{1}\left[\right.$ ] Gabriela Gruszynski Sanseverino ${ }^{2} \cdot$ Mathias-Felipe de-Lima-Santos $^{3} \cdot$ Marcos G. Quiles $^{1}$
}

Received: 4 November 2020 / Revised: 21 April 2021 / Accepted: 24 April 2021 / Published online: 19 May 2021

(c) The Author(s), under exclusive licence to Springer-Verlag GmbH Austria, part of Springer Nature 2021

\begin{abstract}
Fact-checking verifies a multitude of claims and remains a promising solution to fight fake news. The spread of rumors, hoaxes, and conspiracy theories online is evident in times of crisis, when fake news ramped up across platforms, increasing fear and confusion among the population as seen in the COVID-19 pandemic. This article explores fact-checking initiatives in Latin America, using an original Markov-based computational method to cluster topics on tweets and identify their diffusion between different datasets. Drawing on a mixture of quantitative and qualitative methods, including time-series analysis, network analysis and in-depth close reading, our article proposes an in-depth tracing of COVID-related false information across the region, comparing if there is a pattern of behavior through the countries. We rely on the open Twitter application programming interface connection to gather data from public accounts of the six major fact-checking agencies in Latin America, namely Argentina (Chequeado), Brazil (Agência Lupa), Chile (Mala Espina Check), Colombia (Colombia Check from Consejo de Redacciín), Mexico (El Sabueso from Animal Polótico) and Venezuela (Efecto Cocuyo). In total, these profiles account for 102,379 tweets that were collected between January and July 2020. Our study offers insights into the dynamics of online information dissemination beyond the national level and demonstrates how politics intertwine with the health crisis in this period. Our method is capable of clustering topics in a period of overabundance of information, as we fight not only a pandemic but also an infodemic, evidentiating opportunities to understand and slow the spread of false information.
\end{abstract}

Keywords Fact-checking $\cdot$ Twitter $\cdot$ Pandemic $\cdot$ Infodemic $\cdot$ Latin America $\cdot$ Fake news

\section{Introduction}

Fact-checking efforts have been touted among the most promising solutions to fight falseness and information with the intent to harm (Tandoc 2019; Tambuscio and Ruffo 2019). In fact, fact-checking became an important endeavor

Wilson Ceron

wilson.seron@unifesp.br

Gabriela Gruszynski Sanseverino

gabriela.gruszynski-sanseverino@univ-tlse3.fr

Mathias-Felipe de-Lima-Santos

mdelimas@unav.es

Marcos G. Quiles

quiles@unifesp.br

1 Federal University of Sao Paulo, Av. Cesare Mansueto Giulio Lattes, 1201 São José dos Campos, Brazil

2 University of Toulouse III - Paul Sabatier, 115d Route De Narbonne, 31077 Toulouse Cedex 4, France

3 University of Navarra, Campus Universitario s/n, Pamplona, Spain to mitigate the effects of false information after the recognition that misinformation has a high potential to impact society (Tambuscio et al. 2018). This is especially true after 2016, followed by the US presidential election, marked by the heavy fake news rhetoric. Since then, it is recorded an increasingly rising of fact-checking initiatives across the globe. The practice is defined by assessing the validity of claims made by institutions or public people "to identify whether a claim is factual" (Walter et al. 2020). Thus, the idea behind it is to provide information to improve public discourse.

These false or misleading narratives have been exacerbated by the social media platforms. Conversely, social network sites use homophily and popularity mechanisms as the primary determinant of social interactions (McPherson 2001). This can be traced back to social media platforms' origin, which is built on network externalities-i.e., their value directly depends on the number of users (Katz and Shapiro 1985). Users see the benefit of interacting with relatives and friends, giving rise to engagement inside the 
platform, which will also draw in more members (Lin and $\mathrm{Lu}$ 2015).

In this way, controversial content is an important part of their structure, as homophilous means connecting individuals of similar tastes or opinions (Himelboim et al. 2013). Based on these features, users are pushed to engage with content that is aligned with their ideological views. In this respect, the corrections posted by fact-checkers might lead users to strengthen misperceptions, instead of elucidating them. Known as the "backfire effect" (Himelboim et al. 2013; Wood and Porter 2017), it happens when people strengthen their belief in the misconception, rather than rectifying it after exposure to an evidence-based correction.

On the other hand, fact-checking organizations' claims of nonpartisan and non-political are not always taken in consideration by the public. Overall these initiatives do not make clear how they pick and choose what to scrutinize (OeldorfHirsch et al. 2020). Thus, selective perception is an issue for the fact-checking industry. Fact-checkers "are human beings subject to the same psychological biases as everyone else" (Ceci and Williams 2020). This has generated accusations of conflicts in the logic that guide the operation of these sites, which have also been challenged with accusations of political bias (Dobbs 2012). This elucidates the importance of understanding what topics actually are covered by these organizations.

Furthermore, in times of crises, such as the COVID-19 pandemic, fact-checkers are primarily useful in detecting accidental mistakes, rumors, or false narratives. In addition, the novelty of this strain of the coronavirus that spread quickly throughout the world meant that no one has yet been able to understand the etiology of the pandemic, resulting in uncertainty and fear among the public. This mix of facts, fears, rumors, and speculations provided fertile ground for the dissemination of misleading information and cybercrime on the Internet and became an issue to deal with along with the pandemic itself (Pariser 2012; Wagner 2020). The World Health Organization (WHO) went as far as stating that fake news "spreads faster and more easily than" (Cucinotta and Vanelli 2020) a virus and declared a COVID-19 "infodemic"-a period overabundance of the same information, that had to be tackled alongside the pandemic itself. This dire situation that caused an abundance of content being shared online showed the profound necessity of fact-checking initiatives to combat disinformation (Miller and Conover 2015); similarly to a period of elections, when fact-checking traditionally peaks (Coddington et al. 2014).

In this context, our article proposes to study the diffusion of so-called fake news under the lens of fact-checking initiatives' debunks in Latin America. We conducted an indepth tracing of COVID-related false information across the region, comparing if there is a pattern of behavior in the debunks of six different countries. Though several studies have reported on the development of fake news and fact-checking organizations in Western societies, little attention has been given to the Global South, more specifically Latin America. Our research aims at filling this gap by drawing on a computational method associated with a mixture of quantitative and qualitative methods to study this topic from the perspective of six countries in the region.

In particular, we propose to answer the following research questions:

(RQ1) How are these topics intertwined between the different countries?;

(RQ2) What are the topics that fact-checking initiatives in Latin America covered during the pandemic?

(RQ3) How are these topics impacted by politics during the period considered?

To address this phenomenon, this article relies on the open Twitter application programming interface (API) connection to gather data from public Twitter accounts of the six major fact-checking agencies in Latin America, namely Argentina (Chequeado), Brazil (Agência Lupa), Chile (Mala Espina Check), Colombia (Colombia Check from Consejo de Redacciín), Mexico (El Sabueso from Animal Polótico), and Venezuela (Efecto Cocuyo). In total, these accounts account for 102,379 tweets that were collected from January 2020 until July 2020, the first wave of COVID-19 infections.

In this study, we combined a Markov-based computational method (Vermeer and Trilling 2020; Ceron et al. 2021) to cluster topics found on short text, like tweets, with network analysis to investigate the dissemination of fake news content across these countries. After careful data processing, we built a Markov-chain-inspired network for each of six countries, which was used after to draw a graph that shows the relations between the tweets' contents of these fact-checking organizations. After performing this network analysis, we also conducted a time-series analysis and indepth close reading to understand the diffusion of false or misleading narratives in these six countries over the time frame considered.

Our study offers relevant new insights into the dynamics of the dissemination of disinformation online beyond the national level, which poses a threat to society as it has the potential to reach people around the world. Also, our results demonstrated how political disinformation is intertwined with the health crisis during this period considering these six Latin American countries. Last, our method is capable of clustering similar topics in a period known as an infodemic, i.e., containing redundant information, which is consistently backed by our analysis. The contributions made in this study have wide applicability, including slow the spread of false information across countries. 
This article is structured as follows. Section 2 describes the literature framework used to understand the diffusion of false and misleading information, while Sect. 3 discusses the data and methodology adopted in this study. Our analysis and discussion are then presented in Sect. 4. We conclude with final remarks and a discussion of future directions in the final section.

\section{Literature review}

\subsection{Works on fake news and social media}

The value of information is more than ever in question. The term fake news has gained popularity in the context of Donald Trump's election for the presidency of the USA in 2016 and the departure of the UK from the European Union (commonly referred to as Brexit), although it has always been a central element of communication (McNair 2017a). And now, within a digital society, where there is an overabundance of information, increased speed and immediacy, and everyone has a voice in social media, the spread of rumors and misinformation is growing fast (McNair 2017b). Questioning the status quo and the veracity of events is positive and necessary in a democracy. However, there must be minimal consensus on the facts, especially those of public interest. The large volume of news in the public sphere in the era of fake news often puts into question the way things happened in reality and reduces people's ability to differentiate the real from the invented.

The popularization of fact-checking initiatives is inserted in a context of dissemination of false information at the most different levels and although they have existed since the 1990s, fact-checking has grown in quantity and scope in Latin America (Schwartz 2020). Prior research suggests that fact-checking resurfaces as a 'reform movement' that seeks to rescue principles that guided modern journalism, especially truth (Graves 2016). In this scenario, these initiatives gain notoriety by presenting themselves as an alternative to guarantee the public information whose veracity has been previously checked.

The potential harmfulness of fake news is magnified when we consider how new technologies are being used together. Deep fakes, unethical algorithms, and filter bubbles are some examples that put into question the way one looks at reality today, affecting aspects of life that go beyond elections. The algorithms created by social networks gave users established filter bubbles (Pennacchiotti and Popescu 2011; Pariser 2012; Bruns et al. 2017) in our society to do what they want us to do and, thus, it ended up generating more trust in users' content than in the stories published by conventional media (Vraga et al. 2020). Filter bubbles also matter for media and fact-checking initiatives, because, as these organizations corrected and verified news, they find difficulty in reaching precisely the users who most need to see it.

Once more, history brings us to the verge of a health crisis that cannot be spared from the phenomenon of fake news. The H1N1 epidemic in 2009, the Ebola epidemic in West Africa in 2014, and debates on vaccines were examples of fertile grounds for the spread of erroneous or misleading contents (Tambuscio et al. 2018; Abramowitz et al. 2017; Hornsey et al. 2018). However, disinformation about COVID-19 seems to constitute an emblematic case because of both the number and the diversity of false or inaccurate news conveyed in their scope and impacts. As a result, the neologism "infodemic" was put forward on February $2^{\text {nd }}, 2020$, by the World Health Organization, to designate this situation and its dangers (WHO 2020). This pandemic has changed the fact-checking landscape, as managing rumors, dispelling misinformation and conspiracy theories have also become essential to combat the spread of the coronavirus (Dobbs 2020). For novel pandemic diseases, with developments happening in realtime, this becomes a challenge. When social media users began to play a role in all stages of knowledge translation, spreading fake news about the disease and its management became the norm. Thus, this situation has naturally become even more problematic, as we are seen with the COVID-19 pandemic.

Although the so-called fake news has become commonplace, the power of misleading or false information should not be underestimated, as they sow confusion and often cause panic. Platforms, such as Facebook, Instagram, YouTube, and Twitter, have begun to delete information that goes against health guidelines, even when it has been shared by personalities from the political world, such as videos showing Brazilian President Jair Bolsonaro breaking the rule of social distancing, minimizing the epidemic and defending the use of chloroquine (Walter et al. 2020). Another example was messages from Venezuelan President Nicolas Maduro regarding a so-called natural remedy for COVID-19 mixing lemongrass, ginger, and water (Lyons 2020). Also, posts from the former New York City mayor and Donald Trump's personal lawyer Rudy Giuliani defending chloroquine were deleted. These examples allow us to outline important points regarding the spread of fake news surrounding the coronavirus pandemic.

First, there is a strong politicization of information exchange (conspiracy theories, accusations between states, among others), and the divisions, political and ideological, that seem to stir up on social media platforms (Monnier 2020). Beyond being a medical condition with "technical" solutions and a health crisis, the pandemic enters the political field, intrinsically linked to how governments and political leaders are handling the crisis. 
Second, the biggest web platforms are facing an avalanche of misleading content (Creech 2020), especially linked to the pandemic, from miraculous cures, racist explanations of the origin of the coronavirus, or even conspiracy theories (Bruns et al. 2020; de Matos 2020; Havey 2020; Singh et al. 2020). And in the end, each platform must develop a response strategy (Creech 2020). The coronavirus is gaining ground and with it false information (Nguyen and Nguyen 2020). A few hours after the speech by the World Health Organization, which made the coronavirus outbreak an "international public health emergency" (Cucinotta and Vanelli 2020), Facebook, Google, and Twitter took turns implementing mechanisms to contain the spread of false information on their networks (Hutchinson 2020). Twitter pledged to help the world have access to reliable information about coronavirus, a complex task when in January 2020, the platform already listed more than 15 million tweets on the subject.

However, these examples do show an unprecedented practice by social networks of intervening in cases of fake news, which could mark a turning point in the policy of moderation of platforms, often criticized before for a certain carelessness (Monnier 2020). A commitment from these networks, which are assuming their role and responsibility as content editors - in an embrionary form as it may behave been attempting to tackle the problem of disinformation head-on by deleting problematic messages, even when these emanated from legitimate public figures (Monnier 2020). As fact-checking agencies are overwhelmed by the sheer number of fake news circulation on the different platforms and have to make the hard choice of what to debunk-considering the possible implications and reach of each misinformation circulating online, platform taking responsibility is another step to help control the infodemic that surged alongside the spread of the coronavirus.

\subsection{Works on Twitter}

Rumors, misinformation, and false information on social media have been a global issue that is exacerbated during and after disasters and emergencies. Several methods are reported in the literature to address this issue. Among Twitter-based studies, a rich body of work has been carried out using sentiment analysis to understand users' perceptions (Zeng et al. 2007; Francia et al. 2019). Other studies have combined social network analysis with sentiment analysis to take a step further on their analysis (Meyer and Reiter 2004; Bruns et al. 2020). However, a new wave of studies has been exploring how to use social networks to classify topics (Himelboim et al. 2017) or even identify users' roles and actions in political conversations (Santos and Maurer 2020; Cossu et al. 2016). Topic models, such as the latent Dirichlet allocation (LDA) method, became the norm to extract the main subject of the texts (de Souza et al. 2020). However, previous studies have identified that some of those methods, like LDA, require more lexicon and more corpus (Zhao et al. 2011; Hong and Davison 2010; Ceron et al. 2021).

Also, the substantial advances in computational power helped to improve algorithm precision to introduce novel methods for the identification of important topics in social networks. An example is trend-detecting algorithms based on hidden Markov models that use trained models to find observations of topics in a dataset (Zhao et al. 2013; Liu and Guo 2011). Similarly, other methods for the identification of topics in social networks emerged from network topology (Budak et al. 2011). Another approach was using a dictionary learningbased framework for topic modeling in social media (Kasiviswanathan et al. 2011). Last, but important, LDA together text mining techniques became two of the most popular, if not the most ones, forms to identify topics nowadays (Blei et al. 2003; de Souza et al. 2020). On the other hand, tweets are compromised to only 280 characters, which limits their corpus, challenging to cluster topics using LDA, as shown in previous studies (Zhao et al. 2011; Hong and Davison 2010).

Despite these limitations, several approaches highlight the contribution of Twitter in the extraction of knowledge that could be useful to understand, for instance, political leanings or views (Pennycook et al. 2018). Inclusively, recent studies have combined time-series analysis and network analysis to identify the evolution of disinformation in social media (Bruns et al. 2020; Zhao et al. 2013). Methodology-wise, combining social network analysis with different techniques provides a stronger and novel way to explore information in social media.

A new approach is therefore needed for understanding the diffusion of false information on Twitter and in social media in general. Therefore, our work aims to fill this gap as it differs in several key points from the aforementioned studies. The vast majority of methods focus on the classification of topics in large corpora, while our proposed methodology presents a framework for the extraction of similar content using different Twitter accounts and limited corpora. Inspired by the Markov chains, our approach creates clusters of topics that have similar content or keywords. In this way, we can combine different datasets to find these clusters to understand the similarity of these topics. Moreover, we combine this Markov-inspired method with time-series analysis and qualitative approach to have a better understanding of the problem studied. Below, we describe the data and methods used in this study.

\section{Data and methods}

\subsection{Data description}

Our study focuses on the tweets published between January and July 2020 from the profiles of six of the major 
fact-checking agencies from Latin America (see Table 1). Chequeado, from Argentina, has been online since 2010, and it is the first portal in Latin America dedicated to factchecking. The initiative is a non-partisan and non-profit digital medium, dedicated to verifying public discourse and fighting disinformation. In the same vein, Agência Lupa was founded in 2016 and is the first organization to fully dedicate to fact-checking in Brazil. As a news agency, it sells its debunked reports for publication in other outlets and is also part of Facebook's third-party fact-checking program. Beyond that, the Brazilian initiative developed educational programs that promote training, workshops, and lectures on fact-checking and disinformation.

Another organization that is emerging in the region is Mala Espina Check, an independent project that started in 2019. The initiative proposes to contribute to the Chilean citizenship fight against misinformation and be a tool for the community, clarifying doubts about incorrect information that appears, above all, on social networks. ColombiaCheck, founded in 2016, is a project of Consejo de Redacción, a non-profit, non-partisan organization, that brings together more than 100 associated journalists in Colombia to promote investigative journalism. The project consists of a digital, open and collaborative platform based on fact-checking.

Similarly, El Sabueso is the fact-checking branch of the Mexican news outlet, Animal Político, and it seeks to present the true facts unaffected by agenda or biases. Last, Efecto Cосиyo is a Venezuelan website devoted to independent media. The organization was founded in early 2015 by three experienced journalists, who decided to join after recent issues of censorship in Venezuela. Efecto Cocuyo was first launched on Twitter but its portal went to air after receiving funding from the public and international philanthropic foundations. Since then, it has become an important source of information about Venezuela. Beyond investigative reporting, the outlet has also dedicated itself to debunk misand disinformation about Venezuela.

The selection of these organizations was motivated by two reasons. First, they are widely recognized in the factchecking scene and follow the transparency standard of the International Fact-Checking Network (IFCN), an alliance that abides by to promote excellence in fact-checking (IFCN 2012). Second, these outlets are widely present in social media and use their Twitter accounts to disseminate information and debunks. In this way, we could collect a total of 102,379 tweets from these six initiatives. Before we conducted our analysis, we filtered the tweets that were not related to fact-checking. After data cleansing, our dataset was composed of 100,916 tweets. In the case of Efecto Cocuyo, the organization does not have a detached account to disseminate debunks. However, the Venezuelan outlet uses the hashtag \#CocuyoChequea when a tweet is related to its fact-checking branch. This was used for further cleaning.

\subsection{Data preparation}

Our dataset was composed of tweets and their metadata in two languages, Spanish and Portuguese. Before assembling the pool of data for our computational method, a pre-processing phase was necessary. In general, Twitter data have a lot of noise among words. In this step, we eliminated stop words and punctuation signs that were not necessary to understand the context and meaning of the tweets. Additionally, the signals of "RT" from the retweets, mentions (@), and hashtags (\#) were also removed. Lastly, we also evaluated the different models of lexicons for Spanish and Portuguese languages to map common words or expressions that were not relevant and could be removed from the data. To illustrate, fact-checking expressions, such as "This is false" and "We verified," were removed.

After a devised pre-processing strategy, these tweets were used to build a network, which was inspired by Markov chains. These are an important mathematical tool in stochastic processes and are commonly applied to a myriad of fields, such as economics and finance. In finance, it can be used to predict macroeconomic situations like cycles between recession and expansion or even market crashes. Also, banks use Markov chains to predict asset and option prices or calculate credit risks. In communications, prior studies used Markov chains to describe the news user journey while navigating in a news portal (Vermeer et al. 2020; Viner 2016). However, the application of Markov chains is

Table 1 Information about the studied fact-checking organizations

\begin{tabular}{llll}
\hline Agency & Country & News Site & Twitter Handle \\
\hline Chequeado & Argentina & https://chequeado.com/ & https://twitter.com/Chequeado \\
Agencia Lupa & Brazil & https://piaui.folha.uol.com.br/lupa/ & https://twitter.com/agencialupa \\
Mala Spina Check & Chile & https://www.malaespinacheck.cl/ & https://twitter.com/malaespinacheck \\
Colombia Check & Colombia & https://colombiacheck.com/ & https://twitter.com/Colcheck \\
El Sabueso (Animal Politico) & Mexico & https://www.animalpolitico.com/coron & https://twitter.com/ElSabuesoAP \\
& & avirus-covid-19/ & https://twitter.com/EfectoCocuyo \\
Efecto Cocuyo & Venezuela & https://efectococuyo.com/ &
\end{tabular}


yet limited in communications (Vermeer et al. 2020; Vermeer and Trilling 2020).

\subsection{Data analysis}

In our study, a graph $G=(V, E)$ is generated composed of the vertices $V=\left\{v_{1}, v_{2}, v_{3} \ldots v_{n}\right\}$, which here represent the words that pertain a tweet after pre-processing, and the edges $E=\left\{e_{1}, e_{2}, e_{3} \ldots e_{m}\right\}$, which represent a sequence of words, i.e., if two words are followed in a sentence, they are connected by an edge. To illustrate this, we built Fig. 1 based on the sentence below from Efecto Cocuyo:

\#CocuyoChequea Es falso que Unicef informara que si el virus se expone a una temperatura de 26 a 27 grados muere \#CoronavirusFacts \#PrevenirCOVID19

After the preprocessing, the tweet is presented in this way:

\section{UNICEF INFORMARA VIRUS EXPONE TEMPERAT URA GRADOS MUERE}

As it can be seen in Fig. 1, each tweet will be presented with $n=|V|$ vertices and $m=|E|$ edges, which depicts a sequence of words. In this study, the graph is directed, thus, it respects the text structure. In addition, each edge has a weight $W=\left\{w_{1}, w_{2}, w_{3} \ldots w_{m}\right\}$ that represents the number of times two words were connected in the dataset. In fact, this graph concretely demonstrates the relation between two words visually and also gives a different weight to the edge of word pairs that repeats in the long run (Cordeiro et al. 2018; Ergüner Özkoç 2020).

For each country, we built a Markov-inspired network that connects words in the sequence that they appear in the tweet (Ceron et al. 2021). Although they were directed graphs, in the network analysis we consider only the most used words in the dataset, i.e., the words with heavier degrees in the graph. The degree refers to the sum of in-degree (number of incoming edges) and out-degree (number of outgoing edges). Furthermore, only the degrees above 10 were retained to highlight only the most frequent words.

After that, each degree was normalized to identify the percentage of occurrences in the country's graph, which was referred to as "weight" in this study. It was necessary to adjust their values to a notionally common scale based on their proportionality in their dataset (i.e., of each factchecking agency). Importantly, only Agência Lupa (Brazil) has its content in Portuguese. Therefore, we translate it using googletrans, a free and unlimited Python library, that translates texts via requests using Google Translate API. A triple was then created following the pattern: source (country), target (word), and weight. The set of triples of the six countries was used to generate an edge-weighted directed graph to represent the common words among the dataset from different countries.

The graph is composed of ordered pair, including the countries set $C=\left\{c_{1}, c_{2}, c_{3} \ldots c_{n}\right\}$ connected to the word set $W=\left\{w_{1}, w_{2}, w_{3} \ldots w_{n}\right\}$, through a weighted and directed edge set $E=\left\{e_{1}, e_{2}, e_{3} \ldots e_{m}\right\}$, corresponding to the weight of a determined word in the country dataset. To better visualize it, the point size of the font uses the weighted degree value of each node. The weighted degree is the sum of all edge weights connected to one node, as defined by (McPherson 2001). This metric was chosen to better visualize the words that have more mentions in the different countries. In addition, the words were clustered according to the frequency that they appear in the countries. Thus, there are several words that are used in more than one country; however, our study only considered the words that were used in at least three countries. We did not consider common words, such as "year," "month," "days," "number," among others.

Fig. 1 An example of a tweet in the graph

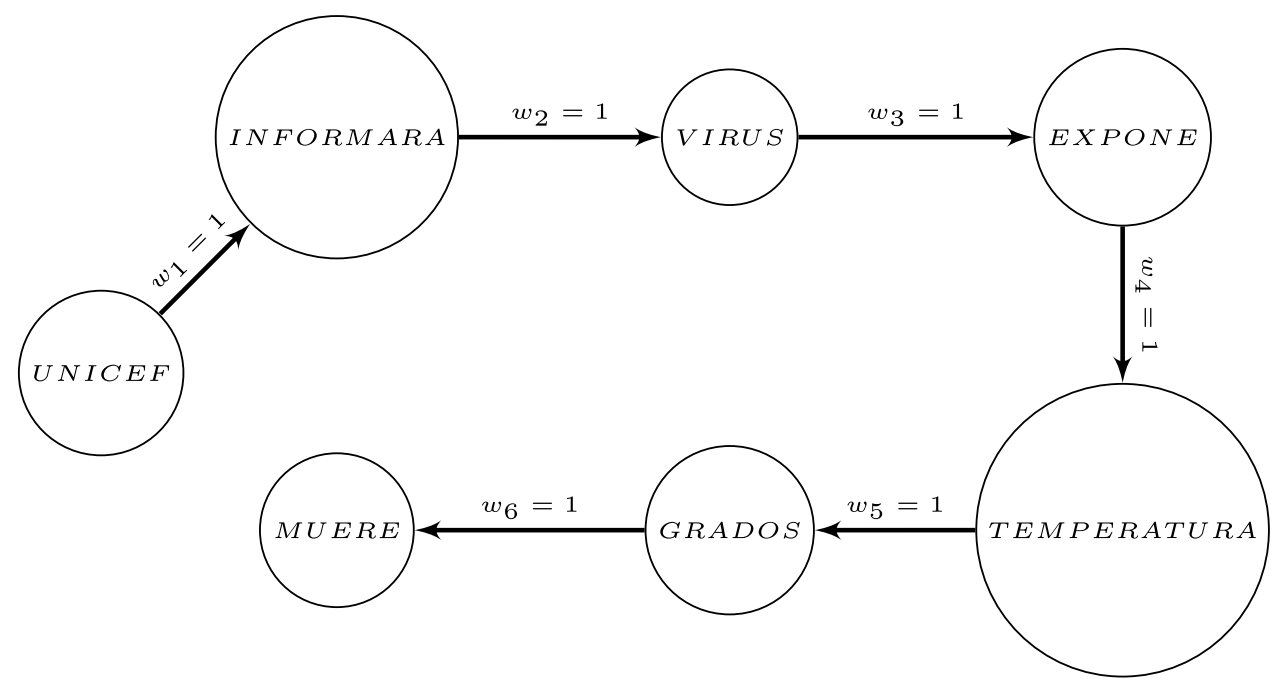


Thus, we could design a graph that could unite the different fluxes of information from the various countries, as shown in Fig. 2, that was implemented in the network analysis software Gephi (Bastian et al. 2009). In it, we could identify topics that were majority diffused across countries to evaluate its evolutions temporally and identify the patterns of dissemination of mis- and disinformation. In Sect. 4.1, we present samples of these false narratives. After that, we present, in Sect. 4.2, time-series analyses of six terms that were highly mentioned by these fact-checking organizations to identify the diffusion over time. These trends represent the mostly used by these organizations: CASOS (cases, in English), CORONAVIRUS, CUARENTENA (quarantine), PANDEMIA (pandemic), VACUNA (vaccine), and lastly, some presidents were highly mentioned during this period. To evaluate the latter, we create a category denoted PRESIDENTS, which covers the mention of each head of state in their respective countries (see Sect. 4.3). To better visualize the evolution of these topics (Figs. 3, 4, 5, 6, 7, 8), we normalized our dataset by calculating the percentage of each term in relation to the total of tweets in a certain period of seven days. Thus, we could achieve consistency in the results that allow us to identify the evolution of these main terms during the pandemic outbreak. In addition, to justify our observations, we crossed our data with links to news articles or fact-checks using googlenews, a Python library to access
Google News API. In the following section, we discuss our findings in relation to these questions and in the light of the theoretical framework described earlier.

\section{Analysis and discussion}

Our results are presented in three sections, each answering one of our research questions. In the first section, we present the validity of our computational method by demonstrating the use of network analysis on how topics are closely interwoven between the different countries (RQ1). We then follow up with a discussion of the topics that were mostly covered during the pandemic by fact-checking initiatives in the six Latin America (RQ2). Lastly, our data show that, in fact, the dissemination of fake news in the pandemic was also impacted by politics during the period (RQ3).

\subsection{The intertwined process of dissemination of disinformation}

We begin this analysis with an overview of the network structure between the topics in relation to the countries during the time frame. In Fig. 2, it is possible to see the edges intertwined in different countries, which means that these words were also mentioned in the other nations. Our

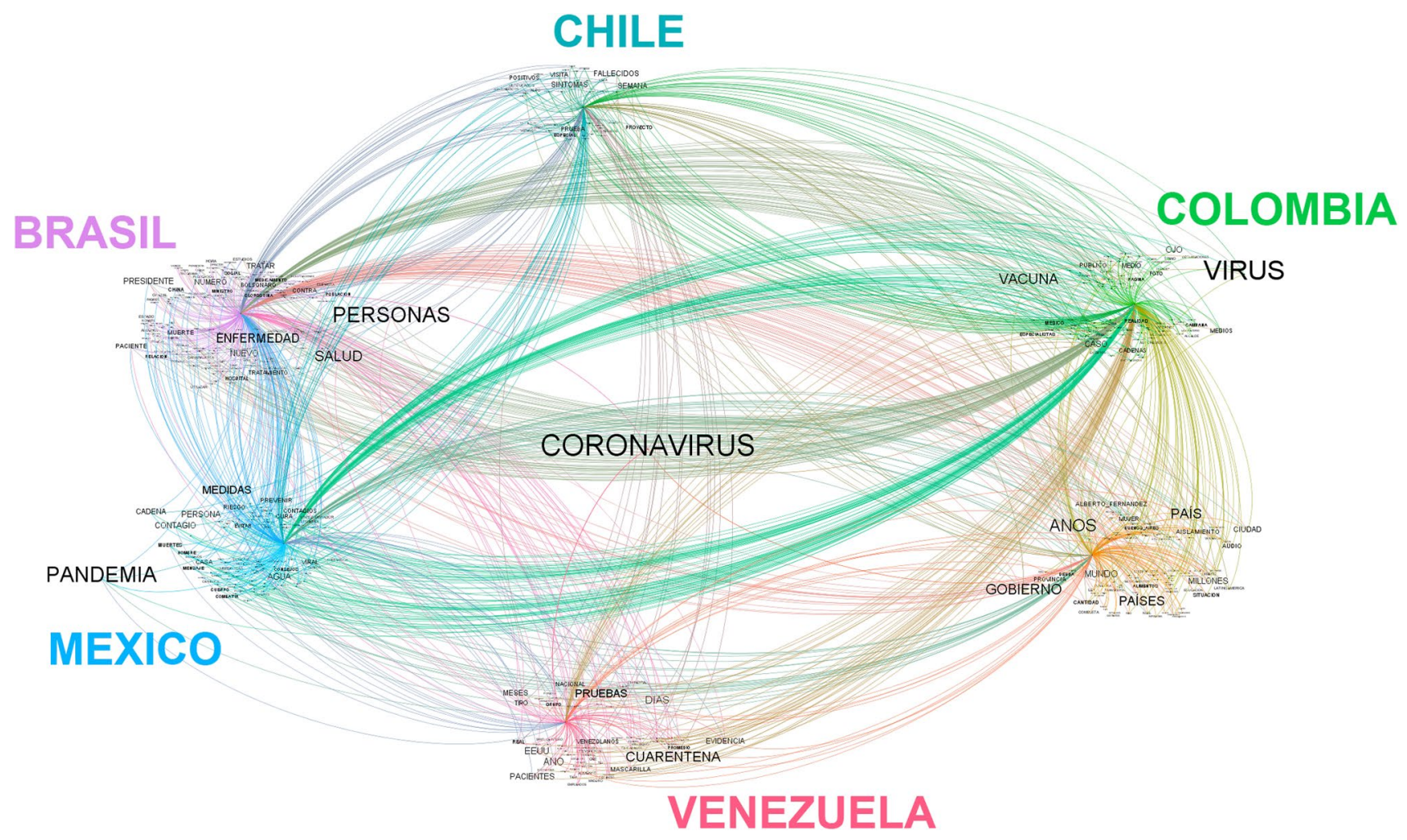

Fig. 2 Relationship between terms in the six countries 
analysis suggests that there are terms that become more evident in certain countries than others. But, on the other hand, it reveals a strong connection between the countries on certain topics.

To simplify, we decided to aggregate the terms COVID19, COVID, and CORONAVIRUS into CORONAVIRUS. As expected, our analysis found evidence that the term coronavirus was one of the biggest concerns of factchecking initiatives during the time frame. This result is consistent with the idea that fact-checking traditionally peaks in the period of crisis (Coddington et al. 2014; Miller and Conover 2015). In addition, it is in line with the alarm sounded by the World Health Organization, which described the health crisis as "infodemic" since there is an overabundance of information-some accurate while others not-that challenges people to understand what are trustworthy and reliable sources (Yuan et al. 2019). Furthermore, the present method confirmed findings that false or misleading information was disseminated beyond their countries of origin. This did not imply that this "fake news" originated in the nations here studied.

By analyzing the network, we can say that the graph is structured more similar to power-law networks than to random networks. This similarity is due to the fact that the countries represent hubs in these networks, while words are the final nodes. In this network, however, high degree nodes are less connected to one another, i.e., the countries.

With respect to the topics that emerged in Fig. 2, it shows that debunks about VACUNA(vaccine) even before it was released, CUARENTENA (quarantine), and the risks and forms of virus transmission were common in the countries here analyzed. In Table 2, we selected some of the most common topics-in at least three countries-that emerged in these fact-checks and potentially show is that were fake news disseminating about them in their respect countries. In our in-depth close reading of some of these topics, we could identify that these fake news revamp and change to stay active for a long time. To illustrate this, Table 2 describes the number of tweets and also includes the dates of the first and last tweet with debunks that covered those topics.

We selected the narratives, for instance, about the dissemination of rumors that the pandemic outbreak was related to the fifth generation technology standard for broadband cellular networks, commonly known as 5G. In Mexico, it was firstly reported $5 \mathrm{G}$ rumors in mid-April and it remains to be seen in the dataset until the end of the period examined in this article. But that is not seen in other examined countries. Three days later, the Chilean fact-checking, Mala Espina Check, also verified rumors about 5G and published the same verification in its Twitter account over April and June. In Colombia, the dissemination of false information drawing connections between COVID-19 and 5G only began to be debunked in May, but continues towards the end of July 2020.

Similarly, Venezuela and Argentina have also shared debunks about conspiracy theories linking $5 \mathrm{G}$ and the pandemic outbreak from May to July 2020. On the contrary, Brazilian fact-checking agency, Agência Lupa, has only published reports that evaluate distinct claims about $5 \mathrm{G}$ in two moments: early-May and end-June. It is notable that in all these countries $5 \mathrm{G}$ is not deployed or is in trial phases, conversely of Western countries that have seen a full expansion of this novel broadband cellular networks. This result ties well with previous studies wherein shows that some false information about $5 \mathrm{G}$ technology has spread around the world during the pandemic (Bruns et al. 2020) and also uncertainty and fear of the unknown are fertile ground for the dissemination of misleading or false information (Pariser 2012; Wagner 2020).

Other fact-check stories that received great prominence in most of the selected outlets are regarding the origin, diagnosis, treatment, prevention, and spread of the virus. There was a substantial common ground in false claims about interventions and practices to help prevent coronavirus. An example is the false claims that lemon juice could inactivate the virus. It started first in Brazil, where a short text was shared in social media that suggested a 'prevention' against COVID19 was to drink a daily dose of water with lemon and vitamin $\mathrm{C}$ at the beginning of March. A couple of days later, in Argentina, the same false claims were shared. Four days later, a Venezuelan deputy made a video sharing a receipt that includes ginger, lemon juice, honey, and pepper as a 'natural' way to protect against the coronavirus.

At the same time, in Colombia, a simple statement was shared on social media: "In the absence of a vaccine, lemon juice" ("A falta de vacuna, jugo de limón," in Spanish). A similar situation happened in Mexico. These stories were being spread from March until the end of the period considered, with different variations. Overall these findings are in line with the ones reported by (Nguyen and Nguyen 2020), who identified the pervasiveness of fake news in social media during this period, "full of false claims, half backed conspiracy theories and pseudoscientific therapies, regarding the diagnosis, treatment, prevention, origin and spread of the virus" (Nguyen and Nguyen 2020). Also, fake news began in the USA, after former president Donald Trump suggested injecting disinfectant to kill coronavirus (BBC 2020). These false stories evolved in Latin America to drink bleach as a way to prevent and cure the coronavirus appeared firstly in Mexico, then later in Venezuela, and Argentina.

A similar pattern of results was obtained in fact-checked content that was published before the pandemic outbreak hit Latin America in March. In January, when Australia was impacted by a bushfire crisis, false stories were disseminated in these countries. First, a satellite image of Australia 
Table 2 Summary of tweets that were common in different Latin American countries

\begin{tabular}{|c|c|c|c|c|}
\hline Country & Organization & $\begin{array}{l}\text { Number of } \\
\text { tweets }\end{array}$ & Date of the first debunk & Date of the last debunk \\
\hline \multicolumn{5}{|l|}{ Vaccine } \\
\hline Argentina & Chequeado & 43 & 21-Feb-2020 & 26-Jul-2020 \\
\hline Brazil & Agência Lupa & 151 & 17-Jan-2020 & 30-Jul-2020 \\
\hline Chile & Mala Espina & 24 & 21-Jan-2020 & 14-Jul-2020 \\
\hline Colombia & Colcheck & 149 & 8-Feb-2020 & 31-Jul-2020 \\
\hline Mexico & El Sabueso & 160 & 27-Feb-2020 & 30-Jul-2020 \\
\hline Venezuela & Efecto Сосиуо & 452 & 19-Mar-2020 & 31-Jul-2020 \\
\hline \multicolumn{5}{|l|}{ Quarantine } \\
\hline Argentina & Chequeado & 140 & 12-Mar-2020 & 28-Jan-2020 \\
\hline Brazil & Agência Lupa & 40 & 28-Jan-2020 & 16-Jul-2020 \\
\hline Chile & Mala Espina & 75 & 18-Mar-2020 & 24-Jul-2020 \\
\hline Colombia & Colcheck & 102 & 12-Feb-2020 & 31-Jul-2020 \\
\hline Mexico & El Sabueso & 88 & 15-Mar-2020 & 29-Jul-2020 \\
\hline Venezuela & Efecto Сосиуо & 402 & 21-Feb-2020 & 31-Jul-2020 \\
\hline \multicolumn{5}{|l|}{$5 G$} \\
\hline Argentina & Chequeado & 20 & 17-May-2020 & 8-Jul-2020 \\
\hline Brazil & Agência Lupa & 7 & 11-May-2020 & 23-Jun-2020 \\
\hline Chile & Mala Espina & 11 & 16-Apr-2020 & 10-Jun-2020 \\
\hline Colombia & Colcheck & 38 & 4-May-2020 & 31-Jul-2020 \\
\hline Mexico & El Sabueso & 52 & 14-Apr-2020 & 29-Jul-2020 \\
\hline Venezuela & Efecto Сосиуо & 126 & 15-May-2020 & 28-Jul-2020 \\
\hline \multicolumn{5}{|l|}{ Lemon } \\
\hline Argentina & Chequeado & 10 & 12-Mar-2020 & 12-May-2020 \\
\hline Brazil & Agência Lupa & 13 & 5-Mar-2020 & 29-Jul-2020 \\
\hline Chile & Mala Espina & - & - & - \\
\hline Colombia & Colcheck & 20 & 18-Mar-2020 & 16-Jul-2020 \\
\hline Mexico & El Sabueso & 91 & 19-Mar-2020 & 29-Jul-2020 \\
\hline Venezuela & Efecto Сосиуо & 14 & 17-Mar-2020 & 1-Apr-2020 \\
\hline \multicolumn{5}{|c|}{ Australia bushfire crisis } \\
\hline Argentina & Chequeado & 6 & 8-Jan-2020 & 15-Jan-2020 \\
\hline Brazil & Agência Lupa & 5 & 9-Jan-2020 & 16-Jul-2020 \\
\hline Chile & Mala Espina & - & - & - \\
\hline Colombia & Colcheck & 24 & 8-Jan-2020 & 19-Apr-2020 \\
\hline Mexico & El Sabueso & 13 & 8-Jan-2020 & 22-Jul-2020 \\
\hline Venezuela & Efecto Сосиуо & - & - & - \\
\hline \multicolumn{5}{|c|}{ Qasem Soleimani } \\
\hline Argentina & Chequeado & - & - & - \\
\hline Brazil & Agência Lupa & 9 & 6-Jan-2020 & 23-Mar-2020 \\
\hline Chile & Mala Espina & 1 & 22-May-2020 & 22-May-2020 \\
\hline Colombia & Colcheck & 3 & 10-Jan-2020 & 24-Jan-2020 \\
\hline Mexico & El Sabueso & 2 & 9-Jan-2020 & 14-May-2020 \\
\hline Venezuela & Efecto Сосиуо & - & - & - \\
\hline \multicolumn{5}{|l|}{ Bleach } \\
\hline Argentina & Chequeado & 6 & 3-Mar-2020 & 17-Jul-2020 \\
\hline Brazil & Agência Lupa & 3 & 13-Mar-2020 & 20-Mar-2020 \\
\hline Chile & Mala Espina & 14 & 4-Feb-2020 & 20-Mar-2020 \\
\hline Colombia & Colcheck & 42 & 11-Mar-2020 & 30-Jul-2020 \\
\hline Mexico & El Sabueso & 63 & 16-Mar-2020 & 30-Jul-2020 \\
\hline Venezuela & Efecto Сосиуо & 190 & 27-Feb-2020 & 1-Jun-2020 \\
\hline
\end{tabular}


burning was shared in Argentina, then the same story was also spread in Colombia. With a slightly different approach, rumors were diffused in Brazil and Mexico that claimed, respectively, humans caused the fires and not a climate change phenomenon. Another false claim argued that the rain ended the wildfires. Similarly, another false story that was repeatedly shared in these countries has related to the assassination of Iranian major general Qasem Soleimani by the US forces while he was on his way to meet Iraqi Prime Minister Adil Abdul-Mahdi in Baghdad. In Brazil, Colombia, and Mexico, rumors were linking politicians to Mr. Soleimani.

The results of the computational experiment found clear support that there is a common ground of topics of rumors and false claims that were disseminated between these countries, based on the important similarities that are visible across the network analysis and in our in-depth close reading of these tweets. Under certain assumptions, this can allow some generalizations that are visible across nations and cultures. Despite these similarities, we could identify that there were also some important differences in terms of the fact-check stories that these outlets debunked to curtail the proliferation of fake news that presented the individuality of each country. Thus, by answering RQ1, this article makes a significant contribution to this debate by proposing an experiment that analyzed the terms that emerged in the debunks of fact-checking initiatives and showed that the disinformation is consistently traveling across nations. Also, we explore how some of these topics also traveled over time from one country to another, suffering adaptations but that maintain their essence. In addition, these fact-checks cover different social media platforms, which potentially show that these misinformation narratives are also traveling across social media platforms.

\subsection{An infodemic that overwhelms us}

In order to answer the research question RQ2, we analyzed the nodes of Fig. 2 that have a large number of connections, not considering words that do not aggregate any information, such as PERSONAS (people). This analysis found evidence again for a period of an overabundance of the same information (Yuan et al. 2019). Our results cast a new light on the evolution of the main false and misleading information spread during the 2020 pandemic. Through a time-series analysis, we could identify the evolution of five main topics based on the tweets that these fact-checking organizations shared during the time frame considered.

Namely, these terms were: CASOS (cases), coronavirus, CUARENTENA or QUARENTENA (quarantine), PANDEMIA (pandemic), VACUNA or VACINA (vaccine). In the following paragraphs, we present these results and illustrate how the diffusion of false claims or rumors were linked to the evolution of the pandemic in the region. In Figs. 3, $4,5,6,7$ and 8 , the values were normalized within each country's dataset, thus, it shows the percentage of tweets in relation to a certain topic in a period of seven days starting on January 1. Of course, the bigger the number, the more debunks can be found in this certain period. We decided to look at a period of seven days, once debunks demand time, and fact-checkers do not always fact-check misleading or false narratives at the exact time they appear. Also, we are looking at topics that are related to fake news, which requires a larger amount of information to identify clusters of topics that exhibit similar behavioral patterns.

The first cases of SARS-CoV2 infection in Latin America were recorded in late February. The confirmation came from Brazil that turned into the first country in the region with the disease (Shawn 2015). In our dataset, we could identify an increasing growth of information debunking that mentioned the term "cases" when the pandemic hit Latin America. From these results, it is clear that countries like Chile, Colombia, Mexico, and Brazil on a smaller scale, suffered from rumors and allegations related to coronavirus cases at the beginning of the pandemic in the region, but it went down after the first weeks, as shown in Fig. 3. In particular, Brazilian debunks about cases lasting throughout the period with a small peak at the end of April led by rumors spreading about asymptomatic cases are not contagious and also a false narrative that there was a reduction in new infection cases around the world (Afonso 2020a, c).

On the other hand, the term "coronavirus" that was merged with similar terms, such as COVID-19 or SARSCoV2, has shown a consistent pattern in most countries during the time frame considered. In particular, Venezuela showed a tendency that was a bit different from the others. The country had a major growth when the first confirmed case appeared in Latin America (Shawn 2015) and since May 2020, it has reduced the number of debunks with the term "coronavirus," "COVID-19," or "SARS-CoV2."

These results led to a conclusion of an overabundance of false information about the virus, with a fallen tendency towards the end of the period analyzed (see Fig. 4). We speculate that this might be due to the fact that the number of cases reached a plateau only by mid-July after a long period of higher levels of infection, resulting in a loss of interest by either the fake news disseminators or the fact-checking initiatives (Buckeridge 2020).

In fact, this can also be seen through the fact-checks related to the term "pandemic" that has been stable or falling since late June, as seen in Fig. 5. Another important finding is that until the World Health Organization announced on March 11th, 2020 (Cucinotta and Vanelli 2020) that the novel coronavirus outbreak was a global pandemic, no factchecks pandemic-related had appeared in these countries. The result of this analysis echoes findings in the academic 
Fig. 3 Evolution of the term "CASOS" (cases) in the time frame

\section{Cases}

\begin{tabular}{|c|c|c|c|c|c|c|}
\hline & ARGENTINA & BRAZIL & CHILE & COLOMBIA & MEXICO & VENEZUELA \\
\hline $01 / 01$ & 2.7 & 5.13 & 0 & 0 & 0 & 0 \\
\hline $08 / 01$ & 2.27 & 0.91 & 0 & 0 & 0 & 0 \\
\hline $15 / 01$ & 3.45 & 4.62 & 1.23 & 3.85 & 0 & 0 \\
\hline $22 / 01$ & 0 & 0 & 0 & 2.33 & 0 & 10.64 \\
\hline $29 / 01$ & 0 & 0 & 0 & 1.09 & 0 & 0 \\
\hline $05 / 02$ & 1.16 & 6.38 & 2.56 & 2 & 0 & 5 \\
\hline $12 / 02$ & 0 & 2.68 & 0 & 2.2 & 0 & 0 \\
\hline $19 / 02$ & 0 & 1.35 & 0 & 3.33 & 0 & 1.35 \\
\hline $26 / 02$ & 0.88 & 0 & 12.66 & 9.89 & 11.11 & 0 \\
\hline $04 / 03$ & 0 & 0 & 14.71 & 12.33 & 0 & 0 \\
\hline $11 / 03$ & 3.19 & 4.5 & 3.8 & 10.98 & 4.12 & 0 \\
\hline $18 / 03$ & 3.12 & 2.29 & 4.23 & 5.26 & 1.58 & 0.45 \\
\hline $25 / 03$ & 1.96 & 1.34 & 3.01 & 4.39 & 0.6 & 0 \\
\hline $01 / 04$ & 0 & 3.33 & 1.52 & 1.63 & 0.53 & 0 \\
\hline $08 / 04$ & 0 & 0.62 & 0 & 1.89 & 0.82 & 0 \\
\hline $15 / 04$ & 0 & 5.07 & 2.63 & 1.75 & 0 & 0 \\
\hline $22 / 04$ & 0 & 5.95 & 1.39 & 1.68 & 0.56 & 0 \\
\hline $29 / 04$ & 0 & 0.74 & 2.38 & 2.06 & 0.49 & 0 \\
\hline $06 / 05$ & 0 & 2.37 & 0 & 0 & 1.56 & 0.96 \\
\hline $13 / 05$ & 0 & 0.76 & 0 & 1.82 & 0.56 & 1.03 \\
\hline $20 / 05$ & 3.96 & 1.14 & 1.45 & 0 & 0.53 & 0.23 \\
\hline $27 / 05$ & 0 & 3.15 & 0 & 0 & 0.59 & 0 \\
\hline $03 / 06$ & 2.06 & 1.4 & 0 & 1.48 & 1.2 & 0 \\
\hline $10 / 06$ & 0 & 0.87 & 1.69 & 0 & 1.42 & 0 \\
\hline $17 / 06$ & 3.37 & 1.41 & 0 & 0.83 & 1.09 & 0 \\
\hline $24 / 06$ & 0.87 & 2.6 & 1.75 & 0 & 1.14 & 0 \\
\hline $01 / 07$ & 1.14 & 0 & 3.77 & 1.54 & 1.62 & 0 \\
\hline $08 / 07$ & 0 & 3.73 & 0 & 4.12 & 0.96 & 0 \\
\hline $15 / 07$ & 0 & 2.33 & 0 & 2.7 & 1.42 & 0 \\
\hline $22 / 07$ & 0 & 6.36 & 0 & 1.83 & 1.03 & 0 \\
\hline $29 / 07$ & 0 & 0 & 0 & 4.88 & 2.33 & 0 \\
\hline
\end{tabular}

literature that shows that periods of uncertainty and fear lead to the dissemination of false information (Cordeiro et al. 2018).
In our time-series analysis, we could also identify that the dissemination of false claims about "quarantine" is another important topic of debate. Our findings show that 
Fig. 4 Evolution of the term "coronavirus" in the time frame

\section{Coronavirus}

\begin{tabular}{|c|c|c|c|c|c|c|}
\hline & ARGENTINA & BRAZIL & CHILE & COLOMBIA & MEXICO & VENEZUELA \\
\hline $01 / 01$ & 0 & 0 & 0 & 0 & 0 & 0 \\
\hline 08/01 & 0 & 0 & 0 & 0 & 0 & 0 \\
\hline $15 / 01$ & 0 & 0 & 0 & 0 & 0 & 0 \\
\hline $22 / 01$ & 1.2 & 12.16 & 4.76 & 3.49 & 20 & 29.79 \\
\hline $29 / 01$ & 4.71 & 14.93 & 20.97 & 4.35 & 13.33 & 32.76 \\
\hline $05 / 02$ & 2.33 & 18.09 & 28.21 & 5 & 0 & 10 \\
\hline $12 / 02$ & 1.08 & | 1.79 & 17.14 & 13.19 & 28.57 & 12.37 \\
\hline $19 / 02$ & 0 & 0 & 15.79 & 1.11 & 0 & 17.57 \\
\hline $26 / 02$ & 0.88 & 16.13 & 20.25 & 8.79 & 22.22 & 55 \\
\hline $04 / 03$ & 0 & 14.1 & 16.18 & 19.18 & 0 & 44.16 \\
\hline $11 / 03$ & 7.45 & 15.32 & 13.92 & 21.95 & 22.68 & 38.61 \\
\hline $18 / 03$ & 16.67 & 26.29 & 14.79 & 18.42 & 7.37 & 40.09 \\
\hline $25 / 03$ & 10.78 & 18.12 & 3.61 & 16.67 & 7.14 & 42.6 \\
\hline $01 / 04$ & 3.37 & 11.33 & 6.82 & 24.39 & 7.89 & 42.01 \\
\hline $08 / 04$ & 9.47 & 13.75 & 8.4 & 9.43 & 9.05 & 42.02 \\
\hline $15 / 04$ & 4.17 & 15.22 & 10.53 & 11.4 & 8.21 & 34.16 \\
\hline $22 / 04$ & 11.76 & 16.76 & 9.72 & 16.81 & 13.97 & 35.49 \\
\hline $29 / 04$ & 17.71 & 18.52 & 15.48 & 19.59 & 13.79 & 29.81 \\
\hline $06 / 05$ & 26.73 & 13.61 & 5.97 & 13.91 & 7.81 & 24.82 \\
\hline $13 / 05$ & 37.78 & 20.61 & 4.55 & 13.64 & 14.44 & 19.9 \\
\hline $20 / 05$ & 35.64 & 10.23 & 10.14 & 11.54 & 14.21 & 14.32 \\
\hline $27 / 05$ & 37.36 & 17.32 & 6.45 & 6.75 & 11.24 & 10.07 \\
\hline $03 / 06$ & 36.08 & 13.29 & 3.28 & 5.93 & 11.95 & 6.16 \\
\hline $10 / 06$ & 28.57 & 10.43 & 5.08 & 9.92 & 10.38 & 5.74 \\
\hline $17 / 06$ & 17.98 & 11.27 & 14.89 & 11.57 & 9.24 & 6.32 \\
\hline $24 / 06$ & 31.3 & 7.14 & 1.75 & 14.16 & 9.47 & 8.32 \\
\hline $01 / 07$ & 13.64 & 16.48 & 9.43 & 12.31 & 12.15 & 7.55 \\
\hline $08 / 07$ & 24.05 & 9.94 & 4.44 & 11.34 & 10.53 & 4.42 \\
\hline $15 / 07$ & 18.18 & 12.21 & 0 & 5.41 & 12.74 & 4.68 \\
\hline $22 / 07$ & 21.92 & 7.51 & 0 & 9.17 & 11.86 & 4.45 \\
\hline $29 / 07$ & 21.95 & 8.6 & 0 & 12.2 & 10.47 & 6.97 \\
\hline
\end{tabular}

there are interests and ideologies underneath the pandemic coronavirus. For example, in Argentina, where quarantine was stricter, the stories and debunks about this topic have been carried out by Chequeado, the Argentine fact-checking organization, during most of the time frame of this study (Di Santi 2020).In the same vein, Venezuela also resented 
Fig. 5 Evolution of the term "pandemia" (pandemic) in the timeframe

\section{Pandemic}

\begin{tabular}{|c|c|c|c|c|c|c|}
\hline & ARGENTINA & BRAZIL & CHILE & COLOMBIA & MEXICO & VENEZUELA \\
\hline $01 / 01$ & 0 & 0 & 0 & 0 & 0 & 0 \\
\hline $08 / 01$ & 0 & 0 & 0 & 0 & 0 & 0 \\
\hline $15 / 01$ & 0 & 0 & 0 & 0 & 0 & 0 \\
\hline $22 / 01$ & 0 & 0 & 0 & 0 & 0 & 0 \\
\hline $29 / 01$ & 0 & 0 & 0 & 0 & 0 & 0 \\
\hline $05 / 02$ & 0 & 0 & 0 & 0 & 0 & 0 \\
\hline $12 / 02$ & 0 & 0 & 0 & 0 & 0 & 0 \\
\hline $19 / 02$ & 0 & 0 & 0 & 0 & 0 & 0 \\
\hline $26 / 02$ & 0 & 0 & 0 & 0 & 0 & 0 \\
\hline $04 / 03$ & 0 & 0 & 0 & 0 & 0 & 0 \\
\hline $11 / 03$ & 4.26 & 4.5 & 1.22 & 2.44 & 4.08 & 0 \\
\hline $18 / 03$ & 4.12 & 5.32 & 0.68 & 2.63 & 2.63 & 0.45 \\
\hline $25 / 03$ & 5.83 & 3.75 & 0 & 2.63 & 2.96 & 0.36 \\
\hline $01 / 04$ & 6.74 & 8.12 & 0 & 12.2 & 5.26 & 3.25 \\
\hline $08 / 04$ & 10.53 & 3.57 & 0 & 6.6 & 4.12 & 2.76 \\
\hline $15 / 04$ & 6.25 & 7.38 & 0 & 14.91 & 8.67 & 2.47 \\
\hline $22 / 04$ & 5.88 & 6 & 1.37 & 10.08 & 7.78 & 4.44 \\
\hline $29 / 04$ & 3.12 & 9.09 & 1.15 & 9.28 & 3.92 & 5.4 \\
\hline 06/05 & 5.94 & 3.87 & 0 & 5.22 & 3.09 & 5.78 \\
\hline $13 / 05$ & 5.56 & 5.76 & 2.99 & 4.55 & 3.87 & 9.56 \\
\hline $20 / 05$ & 1.98 & 4.23 & 0 & 8.65 & 6.19 & 8.22 \\
\hline $27 / 05$ & 2.2 & 5.15 & 0 & 12.88 & 4.68 & 8.2 \\
\hline 03/06 & 7.22 & 2.67 & 1.64 & 6.67 & 7.91 & 4.19 \\
\hline $10 / 06$ & 3.57 & 11.67 & 1.69 & 8.26 & 8.96 & 3.53 \\
\hline $17 / 06$ & 4.49 & 8.78 & 0 & 9.09 & 8.15 & 3.51 \\
\hline $24 / 06$ & 13.91 & 4.49 & 0 & 5.31 & 7.17 & 3.28 \\
\hline $01 / 07$ & 15.91 & 10.11 & 0 & 6.92 & 8.76 & 2.83 \\
\hline 08/07 & 12.66 & 10.91 & 2.22 & 11.34 & 6.22 & 1.98 \\
\hline $15 / 07$ & 3.41 & 4.44 & 0 & 6.31 & 8.96 & 2.64 \\
\hline $22 / 07$ & 8.22 & 5.71 & 0 & 5.5 & 9.28 & 2.29 \\
\hline 29/07 & 7.32 & 5.26 & 0 & 2.44 & 2.33 & 1.74 \\
\hline
\end{tabular}

a consistent level of debunks about this topic since late April 2020, when the Venezuelan government announced the alarm status and also established a "mobility card" to restrict the circulation of people and reduce the effects of the pandemic (Di Santi 2020). On the other hand, in the other countries, debunks about "quarantine" have been far more 
Fig. 6 Evolution of term

"cuarentena" (quarantine) in the time frame

\section{Quarantine}

\begin{tabular}{|c|c|c|c|c|c|c|}
\hline & ARGENTINA & BRAZIL & CHILE & COLOMBIA & MEXICO & VENEZUELA \\
\hline $01 / 01$ & 0 & 0 & 0 & 0 & 0 & 0 \\
\hline 08/01 & 0 & 0 & 0 & 0 & 0 & 0 \\
\hline $15 / 01$ & 0 & 0 & 0 & 0 & 0 & 0 \\
\hline $22 / 01$ & 0 & 1.35 & 0 & 0 & 0 & 0 \\
\hline $29 / 01$ & 0 & 0 & 0 & 0 & 0 & 0 \\
\hline $05 / 02$ & 0 & 0 & 0 & 0 & 0 & 0 \\
\hline $12 / 02$ & 0 & 0 & 0 & 2.2 & 0 & 0 \\
\hline $19 / 02$ & 0 & 0 & 0 & 0 & 0 & 1.35 \\
\hline $26 / 02$ & 0 & 0 & 0 & 1.1 & 0 & 0 \\
\hline $04 / 03$ & 0 & 0 & 0 & 0 & 0 & 0 \\
\hline $11 / 03$ & 7.45 & 0.9 & 0 & 1.22 & 0 & 0 \\
\hline $18 / 03$ & 6.25 & 0.57 & 6.34 & 7.89 & 2.63 & 0 \\
\hline $25 / 03$ & 9.8 & 0.67 & 10.84 & 9.65 & 3.57 & 0 \\
\hline $01 / 04$ & 2.25 & 5.33 & 3.03 & 5.69 & 2.11 & 0.3 \\
\hline $08 / 04$ & 7.37 & 1.88 & 4.2 & 5.66 & 1.65 & 1.84 \\
\hline $15 / 04$ & 5.21 & 0 & 9.21 & 2.63 & 0.51 & 6.17 \\
\hline $22 / 04$ & 1.96 & 0.54 & 4.17 & 0.84 & 3.91 & 5.8 \\
\hline $29 / 04$ & 4.17 & 0 & 1.19 & 1.03 & 0.99 & 6.34 \\
\hline $06 / 05$ & 10.89 & 0 & 2.99 & 5.22 & 5.21 & 7.95 \\
\hline $13 / 05$ & 4.44 & 0 & 15.15 & 0 & 2.22 & 8.53 \\
\hline $20 / 05$ & 17.82 & 0.57 & 4.35 & 0 & 0 & 7.98 \\
\hline $27 / 05$ & 5.49 & 0.79 & 0 & | 0.61 & 0.59 & 6.79 \\
\hline $03 / 06$ & 8.25 & 0 & 1.64 & 1.48 & 1.2 & 6.16 \\
\hline $10 / 06$ & 4.76 & 0 & 1.69 & 0 & 0.94 & 5.96 \\
\hline $17 / 06$ & 7.87 & 2.11 & 2.13 & 0 & 1.63 & 4.45 \\
\hline $24 / 06$ & 11.3 & 0.65 & 0 & 0 & 1.89 & 3.5 \\
\hline $01 / 07$ & 4.55 & 0 & 0 & 0 & 1.21 & 4.72 \\
\hline $08 / 07$ & 0 & $\mid 0.62$ & 0 & 0 & 0.96 & 4.27 \\
\hline $15 / 07$ & 9.09 & | 0.58 & 0 & 0.9 & 1.42 & 4.05 \\
\hline $22 / 07$ & 8.22 & 0 & 6.67 & 0.92 & 1.55 & 3.94 \\
\hline $29 / 07$ & 4.88 & 0 & 0 & 7.32 & 1.16 & 2.09 \\
\hline
\end{tabular}


Fig. 7 Evolution of term "vacuna" (vaccine) in the time frame

\section{Vaccine}

\begin{tabular}{|c|c|c|c|c|c|c|}
\hline & ARGENTINA & BRAZIL & CHILE & COLOMBIA & MEXICO & VENEZUELA \\
\hline 01/01 & 0 & 0 & 0 & 0 & 0 & 0 \\
\hline 08/01 & 0 & 0 & 0 & 0 & 0 & 0 \\
\hline $15 / 01$ & 0 & 1.54 & 3.7 & 0 & 0 & 0 \\
\hline $22 / 01$ & 0 & 0 & 1.59 & 0 & 0 & 0 \\
\hline 29/01 & 0 & 0 & 0 & 0 & 0 & 0 \\
\hline $05 / 02$ & 0 & 0 & 2.56 & 2 & 0 & 0 \\
\hline $12 / 02$ & 0 & 0 & 0 & 0 & 0 & 0 \\
\hline $19 / 02$ & 2.6 & 0 & 0 & 0 & 0 & 0 \\
\hline $26 / 02$ & 2.63 & 0 & 1.27 & 0 & 11.11 & 0 \\
\hline $04 / 03$ & 2.33 & 1.28 & 1.47 & 4.11 & 0 & 0 \\
\hline $11 / 03$ & 1.06 & 4.5 & 0 & 3.66 & 5.15 & 0 \\
\hline 18/03 & 0 & 5.71 & 0.7 & 7.02 & 1.58 & 5.41 \\
\hline $25 / 03$ & 0.98 & 7.38 & 0 & 10.53 & $\mid 0.6$ & 4.33 \\
\hline $01 / 04$ & 0 & 0.67 & 0 & 6.5 & 1.05 & 3.25 \\
\hline $08 / 04$ & 5.26 & 0.62 & 0 & 4.72 & 0 & 4.29 \\
\hline $15 / 04$ & 2.08 & 0.72 & 5.26 & 5.26 & 0 & 10.7 \\
\hline $22 / 04$ & 2.94 & 0 & 5.56 & 7.56 & 2.79 & 8.19 \\
\hline $29 / 04$ & 2.08 & 0 & 0 & 7.22 & 2.46 & 7.75 \\
\hline $06 / 05$ & 0 & 2.37 & 0 & 4.35 & 2.08 & 6.27 \\
\hline $13 / 05$ & 1.11 & 0 & 1.52 & 9.09 & 1.11 & 4.65 \\
\hline $20 / 05$ & 0 & 0.57 & 0 & 4.81 & 2.63 & 4.23 \\
\hline $27 / 05$ & 2.2 & 3.94 & 0 & 4.29 & 1.18 & 1.17 \\
\hline 03/06 & 0 & 2.8 & 0 & 2.96 & 2.39 & 0 \\
\hline $10 / 06$ & 3.57 & 2.61 & 5.08 & 10.74 & 3.77 & 1.55 \\
\hline $17 / 06$ & 0 & 15.49 & 2.13 & 2.48 & 4.89 & 3.28 \\
\hline $24 / 06$ & 0 & 1.3 & 0 & 4.42 & 3.41 & 2.84 \\
\hline $01 / 07$ & 0 & 11.36 & 3.77 & 3.85 & 3.64 & 2.83 \\
\hline 08/07 & 0 & 4.35 & 2.22 & 1.03 & 3.83 & 2.28 \\
\hline $15 / 07$ & 1.14 & 8.14 & 0 & 3.6 & 3.3 & 1.64 \\
\hline $22 / 07$ & 2.74 & 13.87 & 0 & 0.92 & 4.12 & 0.76 \\
\hline 29/07 & 0 & 9.68 & 0 & 2.44 & 3.49 & 0.7 \\
\hline
\end{tabular}


Fig. 8 Evolution of term "presidente" (president) in the time frame

\section{President}

\begin{tabular}{|c|c|c|c|c|c|c|}
\hline & ARGENTINA & BRAZIL & CHILE & COLOMBIA & MEXICO & VENEZUELA \\
\hline $01 / 01$ & 14.86 & 7.69 & 1.3 & 0 & 0 & 0 \\
\hline 08/01 & 15.91 & 5.45 & 0 & 0 & 0 & 0 \\
\hline $15 / 01$ & 4.6 & 7.69 & 8.64 & $\mid 1.28$ & 18.75 & 0 \\
\hline $22 / 01$ & 1.2 & 5.41 & 1.59 & 0 & 20 & 0 \\
\hline $29 / 01$ & 7.06 & 4.48 & 0 & 0 & 0 & 0 \\
\hline $05 / 02$ & 5.81 & 3.19 & 0 & 0 & 0 & 0 \\
\hline $12 / 02$ & 6.45 & 9.82 & 0 & 0 & 0 & 0 \\
\hline $19 / 02$ & 12.99 & 6.76 & 0 & | 1.11 & 0 & 0 \\
\hline $26 / 02$ & 42.98 & 22.58 & 0 & 0 & 0 & 0 \\
\hline $04 / 03$ & 17.44 & 2.56 & 1.47 & 0 & 0 & 0 \\
\hline $11 / 03$ & 11.7 & 9.01 & 6.33 & 1.22 & 0 & 0 \\
\hline $18 / 03$ & 0 & 2.29 & 0 & $\mid 0.88$ & 1.58 & 0 \\
\hline $25 / 03$ & 3.92 & 6.04 & 1.2 & $\mid 0.88$ & 5.36 & 0 \\
\hline $01 / 04$ & 1.12 & 4.67 & 0 & 0 & 6.84 & 0 \\
\hline $08 / 04$ & 5.26 & 1.88 & 0.84 & 1.89 & 4.12 & 0 \\
\hline $15 / 04$ & 3.12 & 3.62 & 1.32 & 0 & 0.51 & 0 \\
\hline $22 / 04$ & 1.96 & 10.81 & 0 & $\mid 0.84$ & 3.35 & 0 \\
\hline $29 / 04$ & 1.04 & 1.48 & 0 & 3.09 & 3.45 & 0 \\
\hline 06/05 & 7.92 & 2.96 & 0 & 2.61 & 7.29 & 0 \\
\hline $13 / 05$ & 2.22 & 2.29 & 6.06 & 0.91 & 3.89 & 0 \\
\hline $20 / 05$ & 3.96 & 10.8 & 0 & 0 & 2.63 & 0 \\
\hline $27 / 05$ & 4.4 & 4.72 & 0 & 0 & 1.78 & 0 \\
\hline $03 / 06$ & 6.19 & 3.5 & 0 & $\mid 0.74$ & 2.39 & 0 \\
\hline $10 / 06$ & 3.57 & 1.74 & 0 & 0 & 2.83 & 0 \\
\hline $17 / 06$ & 0 & | 0.7 & 2.13 & 1.65 & 6.52 & 0 \\
\hline $24 / 06$ & 1.74 & 10.39 & 1.75 & 1.77 & 2.65 & 0 \\
\hline $01 / 07$ & 0 & 8.52 & 11.32 & $\mid 0.77$ & 4.86 & 0 \\
\hline $08 / 07$ & 2.53 & 11.18 & 2.22 & 0 & 2.87 & 0 \\
\hline $15 / 07$ & 7.95 & 4.65 & 0 & \begin{tabular}{|l|l|} 
& 1.8
\end{tabular} & 1.89 & 0 \\
\hline $22 / 07$ & 0 & 4.05 & 13.33 & 3.67 & | 1.03 & 0 \\
\hline $29 / 07$ & 7.32 & 4.3 & 16.67 & 0 & 0 & 0 \\
\hline
\end{tabular}


visible at the beginning of the pandemic than at the end of the period analyzed (see Fig. 6).

The last topic that became more evident across these countries is the "vaccine." Ranging from a canine and bovine vaccines for coronavirus to conspiracy theories leveraged and amplified by malicious actors to promote anti-vax movements. In fact, the academic literature has also shown how these anti-vaxxers are presented on social platforms to problematize and oppose vaccination (Rich 2020; Francia et al. 2019). Also, previous studies have shown the anti-vax users are frequently interacting with each other, strengthening their relationships, and making the information redundant within their community to diffuse false information in line with their beliefs against immunization (Milani et al. 2020).

The fear and uncertainty of vaccination have exacerbated the dissemination of fact-checks about this topic, and consequently, the so-called fake news appeared from the confirmation of the first case in Latin America until the end of the time frame analyzed, with special peaks during the last two months when the vaccines were already in trials worldwide, as seen in Fig. 7. The proportion of disinformation about vaccines is bigger in Brazil, Colombia and Venezuela than in other countries. This can be explained by many reasons. In Venezuela, there was a number of false content related to the use of Bacillus Calmette-Guérin (BCG) vaccine against the COVID-19, which this immunization is primarily used against tuberculosis and there was no proof of the plausibility of efficacy against the novel coronavirus. Also, the country suffered with criminal groups who invaded houses creating false narratives that they were applying vaccines against COVID-19, which, in truth, served to rob those people.

In Colombia, the debunks clarified that there was no vaccine available yet to the population while they were already being developed and tested in other countries. In the case of Brazil, the country took part in several vaccine trials, which generated rumors and fears from the population. The factchecks clarified that there is no evidence of negative effects during this phase. Another reason might be political, as it will be discussed later, as the country's president is prejudiced against the Chinese vaccine (Soares 2020), resulting in misleading information about this vaccine. Also, false information about the trials of Sinovac's vaccine was common, such as the company tested only in monkeys, which was debunked by Agência Lupa(Afonso 2020b). Lastly, the fear that vaccines might work or not and when they will be available has generated many rumors in the country.

\subsection{Politics and Pandemic, a perfect storm}

As mentioned before, our data have also revealed a significant political influence on the debate of the pandemic (RQ3). The political instability and polarization in these countries have influenced a range of false or misleading information. In Brazil, the political turmoil took the agenda of the factchecking agency that had to check more Bolsonaro-related content, from late February to July, as seen in Fig. 8. An example happened when there was fake news related to the former justice minister, Sérgio Moro, who resigned from his position after divergences with the president, which ramped up fake news about the former minister (de Matos 2020). It is by now generally accepted that continued denials of the threat the pandemic poses by Jair Bolsonaro, Brazilian president, who went against his own health ministry's advice and had to change the Minister of Health more than once, have generated considerable dissemination of false information by his supporters.

Figure 8 also shows that there were a great number of mentions in debunks related to heads of states in other countries. In Argentina, they were also suffering from rumors against its president, Alberto Fernández, who decided to adopt a strict lockdown that produced dissatisfaction from his opposition. Similar to Bolsonaro, the Mexican president, Andrés Manuel López Obrador, took a skeptical view on social isolation at the beginning of the crisis, which led to a number of fact-checks about the importance of quarantine. These findings show that politics is strongly intertwined with the health crisis and fake news. Furthermore, this also reveals that political decisions can lead to drastic consequences to the quality of information consumed by society.

\section{Conclusion}

By looking at 102,379 tweets from six major fact-checking agencies, this study allowed us to conclude that the socalled fake news travels beyond countries' borders and are intertwined with the political situation of each country. Our computational method obtained robust results in identifying the main terms that were being used, and through these words, we could find the common topics that arose in these countries. In addition, this method allowed us to detect the COVID-19 narratives without the need to read every single tweet.

In the world, fact-checkers have been playing an important role in showing the fake news that were being spread in their countries (Tandoc 2019). Our study shows that these fact-checking agencies act primarily on social media, such as Twitter, to disseminate their debunks and act as a stop-gap measure to correct the fake news that is being spread in this same environment. These organizations played an active role during the pandemic, which, in some cases, complements governmental activities in the combat of the pandemic. These debunks showed fundamental to diminish the rumors and false narratives, which is putting lives at risk, as seen in 
Argentina, where a kid drank bleach to prevent infection by the coronavirus (LA NACION 2020).

Furthermore, in our network analysis, we identified that the words are strongly connected among these different nations, although our network is structured more similar to a free-scale graph, in which the countries represent the hubs. As expected, our results provide evidence for the period of an abundance of the same information, i.e., an infodemic. The fact-checking agencies have had to debunk false or inaccurate information about cases, coronavirus, quarantine, pandemic, and vaccine that were clearly linked to the evolution of the pandemic in all of these six countries studied. By analyzing these most common terms that have a large number of connections, it shows a strong consistency throughout the entire observation period.

Our findings have also shown that a large part of debunks related to the COVID-19 pandemic emerges at a certain time and continues to threaten citizens for a long period of time. In our in-depth close reading, we could see that this is possible because some fake news revamp and adapt their format to stay active for a long period of time. Also, our analysis showed that some relevant findings related to debunks of international topics, such as the Australia bushfires and the assassination of Iranian major general Qasem Soleimani, are associated to local politicians. These two topics were popularly debunked in the fact-checking initiatives of the countries analyzed but Efecto Cocuyo, the Venezuela factchecking organization. We speculate that this might be due to the escalated political situation in Venezuela after the US sanctions made the country more closed to the outside. Future studies could fruitfully explore this issue further by qualitative study with fact-checkers in Venezuela to understand what they cover and what are the main fake news topics that emerge in the country.

With respect to the influence of politics during the pandemic, it is well-known that the politicization of information has made fake news ramp up across platforms. Broadly translated our findings indicate that politics play an important role in shaping the dissemination of rumors and false information. Misinformation and false information are a profoundly complex issue that involves platforms, governmental institutions, policy reviews, regulatory boards and, as such, these are issues that fact-checking agencies alone will not solve, even though they are an important part of the equation. Looking at the fact-checks, we can say that there are political topics intertwined with the health crisis, which, in some instances, draw the attention of the pandemic. This can lead to drastic consequences, specifically danger to people's lives. Future studies could fully investigate the dynamics between politics and the COVID-19 crisis.

Our original method helped to develop a simple but consistent analysis of the diffusion of "fake news" across Latin American countries. In part, our algorithm worked well due to the similarity between Portuguese and Spanish languages. Future research should certainly test whether debunks of other languages would work as expected. In particular, future studies could examine the dissemination of fake news content in the Americas.

An apparent limitation of the method is that it is based on debunks, which can lead to a selective bias, as these initiatives pick and choose what to scrutinize (Ceci and Williams 2020). Inclusively, scholarly literature has shown that these organizations have been suffering from accusations of political bias due to their selection of content to debunk (Dobbs 2012). Because of these potential limitations, we cannot say that these topics are the only misleading or false narratives disseminated on social media platforms, but these debunks serve to shed light on relevant topics that emerged during the crisis.

Another limitation of this study is that it could be argued that fact-checking initiatives have different forms of dissemination of debunks that can directly influence our results, such as repeated tweets of the same fact-check story or relying on other social media platforms. Therefore, these data are a sample of the fake news narratives disseminated during the period. Further work is certainly required to disentangle these complexities in Latin America, potentially through qualitative research with practitioners to better understand how these organizations interact and relate among them. Also, future research could perform a network analysis over time to have a better understanding of how these topics could be addressed in the future to avoid diffusion beyond where it started.

In fact, we would be remiss if we did not point that there needs to be a joint action by governments, educators, laws, institutions, and platforms, together with fact-checking agencies to circulate proper information content, and also discouraging and stopping disinformation campaigns.

In conclusion, the pandemic has served to consolidate the need for and an awareness of the importance of this branch in the journalistic sector (Monnier 2020), despite its limitations (Bigot 2019). We argue that it is undeniable that factchecking initiatives, just as journalism itself, are essential to combat the spread of misinformation online. We argue that, despite all shortcomings, these fact-checks represent a strong indicator of the main fake narratives that are disseminated in the countries, which shed light on relevant topics that emerged on social media platforms. Finally, our analysis reveals opportunities to understand the diffusion of these "fake news" in Latin American countries to slow the spread of false information, and avoid people getting affected by these narratives in future events.

Acknowledgements This project was partially funded by the European Union's Horizon 2020 research and innovation programme under the Marie Sklodowska Curie grant agreement No 765140. 


\section{References}

Abramowitz S, Lindley MS, Mosoka F, Josephine M, Kodjo T, Omidian PA (2017) The opposite of denial: social learning at the onset of the ebola emergency in liberia. J Health Commun 22(sup1):59-65

Afonso N (2020a) Em site oficial, Saúde erra ao informar que pacientes sem sintomas não transmitem Covid-19. Agência Lupa. https://piaui.folha.uol.com.br/lupa/2020/04/22/minis terio-saude-paciente-sintomas. Accessed $1 \mathrm{Feb} 2021$

Afonso N (2020b) Verificamos: É falso que vacina da Sinovac foi testada apenas em macacos. Agência Lupa. https://piaui.folha. uol.com.br/lupa/2020/06/18/verificamos-vacina-sinovac-macac os/. Accessed 1 Feb 2021

Afonso N (2020c) Verificamos: Post erra ao falar que novos casos de Covid-19 diminuem diariamente no mundo. Agência Lupa. https://piaui.folha.uol.com.br/lupa/2020/04/23/verificamospost-covid-diminuem/. Accessed 1 Feb 2021

Bastian M, Heymann S, Jacomy M (2009) Gephi: an open source software for exploring and manipulating networks. In: Third international AAAI conference on weblogs and social media

BBC (2020) Coronavirus: Outcry after Trump suggests injecting disinfectant as treatment. BBC News. https://www.bbc.com/news/ world-us-canada-52407177. Accessed 28th Jan 2021

Bigot L (2019) Fact-checking vs fake news: Vérifier pour mieux informer, 1 st edn. Études et controverses. Institut National de l'Audiovisuel, Paris

Blei DM, Ng AY, Jordan MI (2003) Latent Dirichlet Allocation. Journal of Machine Learning Research. 4-5(3):993-1022

Bruns A, Harrington S, Hurcombe E (2020) "Corona? 5G? or both?": the dynamics of COVID-19/5G conspiracy theories on Facebook. Media Int. Aust. 17712-29

Bruns A, Moon B, Münch F, Sadkowsky T (2017) The Australian Twittersphere in 2016: mapping the follower/followee network. Social Media Soc 3(4):1-15

Buckeridge MS (2020) Global analysis of the infection by COVID19. Ambiente Sociedade 23:1-10

Budak C, Divyakant A, El Abbadi A (2011) Structural trend analysis for online social networks. Proc VLDB Endow 410:646-656

Ceci SJ, Williams WM (2020) The psychology of fact-checking. Scientific American. https://www.scientificamerican.com/artic le/the-psychology-of-fact-checking 1/. Accessed 29 Jan 2021

Ceron W, de Lima-Santos MF, Quiles MG (2021) Fake news agenda in the era of COVID-19: identifying trends through fact-checking content. Online Soc Netw Media 21(100116): 1

Coddington M, Logan M, Lawrence RG (2014) Fact checking the campaign: how political reporters use Twitter to set the record straight (or not). Int J Press/Politics 19(4):391-409

Cordeiro M, Sarmento RP, Brazdil P, Gama J (2018) Evolving networks and social network analysis methods and techniques. In: Social Media and Journalism - Trends, Connections, Implications. InTech

Cossu JV, Labatut V, Dugué N (2016) A review of features for the discrimination of twitter users: application to the prediction of offline influence. Soc Netw Anal Min 6(1):1-23

Creech B (2020) Fake news and the discursive construction of technology companies' social power. Media Cult Soc 42(6):952-968

Cucinotta D, Vanelli M (2020) WHO declares COVID-19 a pandemic. Acta Biomedica. 91(1):157-160

de Matos RC (2020) Fake news in face of the COVID-19 pandemic. Vigilância Sanitária em Debate: Sociedade, Ciência \& Tecnologia. 8(3):78-85

de Souza JV, Gomes J, de Souza FFM, de Oliveira JAM, de Souza JF (2020) A systematic mapping on automatic classification of fake news in social media; $10(1): 48$
Di Santi M (2020) Alberto Fernández anunció que la cuarentena se extiende hasta el 7 de junio y que se endurecerá en el AMBA.

Dobbs M (2012) The rise of political fact-checking how reagan inspired a journalistic movement: a reporter's eye view. Technical report, New America Foundation

Dobbs M (2020) Science journalism and pandemic uncertainty. Media Commun 8(2):471

Ergüner Özkoç E (2020) Clustering of time-series data. In: Data Mining-methods, applications and systems. IntechOpen, pp $1-19$

Francia M, Gallinucci E, Golfarelli M (2019) Social BI to understand the debate on vaccines on the Web and social media: unraveling the anti-, free, and pro-vax communities in Italy. Soc Netw Anal Min 9(1):46

Graves L (2016) Deciding what's true, 1st edn. Columbia University Press, New York

Havey NF (2020) Partisan public health: how does political ideology influence support for COVID-19 related misinformation? J Comput Soc Sci 3(2):319-342

Himelboim I, Mccreery S, Smith M (2013) Integrating network and content analyses to examine cross-ideology exposure on Twitter, birds of a feather tweet together 18(2):40-60

Himelboim I, Smith MA, Rainie L, Shneiderman B, Espina C (2017) Classifying Twitter topic-networks using social network analysis. Social Media Soc 3(1):1-13

Hong L, Davison BD (2010) Empirical study of topic modeling in Twitter. In: SOMA 2010-Proceedings of the 1st workshop on social media analytics, pp 80-88

Hornsey Matthew J, Harris Emily A, Fielding Kelly S (2018) The psychological roots of anti-vaccination attitudes: a 24-nation investigation. Health Psychol 37(4):307-315

Hutchinson A (2020) Facebook, Twitter and Google to team up to combat COVID-19 vaccine misinformation. Social Media Today. https://www.socialmediatoday.com/news/facebook-twitt er-and-google-to-team-up-to-combat-covid-19-vaccine-misin for/589510/. Accessed 4 Feb 2021

IFCN (2015) International Fact-Checking Network-Poynter. https:// www.poynter.org/ifcnAccessed 4 Feb 2021

Kasiviswanathan Shiva K, Prem M, Arindam B, Vikas S (2011) Emerging topic detection using dictionary learning. In: International conference on information and knowledge management, proceedings, New York, USA. ACM Press, New York, pp 745-754

Katz ML, Shapiro C (1985) Network externalities, competition, and compatibility. American Economic Review 75(3):424-440

LA NACION (2020) Neuquén: confirman que el chico de cinco años murió por tomar dióxido de cloro. LA NACIÓN. https://www.lanac ion.com.ar/sociedad/neuquen-confirman-chico-cinco-anos-muriotomar-nid2434077/. Accessed 29 Jan 2021

Lin KY, Peng LH (2015) Predicting mobile social network acceptance based on mobile value and social influence. Int Res 25(1):107-130

Ling R (2020) Confirmation bias in the era of mobile news consumption: the social and psychological dimensions. Digit $\mathbf{J}$ 8(5):596-604

Liu R, Guo W (2011) HMM-based state prediction for Internet hot topic. In: Proceedings-2011 IEEE international conference on computer science and automation engineering, CSAE 2011, vol 1 , pp 157-161

Lyons K (2020) Twitter removes tweets by Brazil, Venezuela presidents for violating COVID-19 content rules. The Verge. https://www. theverge.com/2020/3/30/21199845/twitter-tweets-brazil-venez uela-presidents-covid-19-coronavirus-jair-bolsonaro-maduro. Accessed 29 Oct 2020

McNair B (2017a) An introduction to political communication, 1st edn. Routledge, London 
McNair B (2017b) \#FakeNews. In: Fake News, chapter 1st, pages 1-16. Routledge, London, 2017. Series: Disruptions: studies in digital journalism, 6th edn

McPherson M, Smith-Lovin L, Cook JM (2001) Birds of a Feather: Homophily in Social Networks. Annu. Rev. Sociol. 27(1):415-444

Meyer C, Reiter S (2004) Impfgegner und Impfskeptiker. Bundesgesundheitsblatt - Gesundheitsforschung - Gesundheitsschutz 47(12):1182-1188

Milani E, Emma W, Peter W (2020) The visual vaccine debate on Twitter: a social network analysis. Media Commun 8(2):364-375

Miller PR, Conover PJ (2015) Red and blue states of mind. Polit Res Q 68(2):225-239

Monnier A (2020) Covid-19: de la pandémie à l'infodémie et la chasse aux fake news. Recherches \& éducations, (HS)

Nguyen H, Nguyen A (2020) Covid-19 misinformation and the social (media) amplification of risk: a Vietnamese perspective. Media Commun 8(2):444

Oeldorf-Hirsch A, Schmierbach M, Appelman A, Boyle MP (2020) The ineffectiveness of fact-checking labels on news memes and articles. Mass Commun Soc 23(5):682-704

Pariser E (2012) The filter bubble: what the internet is hiding from you. Penguin Books, London

Pennacchiotti M, Popescu A-M (2011) A machine learning approach to twitter user classification. In: Fifth international AAAI conference on weblogs and social media

Pennycook G, Cannon TD, Rand DG (2018) Prior exposure increases perceived accuracy of fake news. J Exp Psychol Gen 147(12): $1865-1880$

Santos CRP, Maurer C (2020) Potencialidades e limites do fact-checking no combate à desinformação. Comunicação \& Informação 23:1-14

Schwartz L (2020) Brazil confirms first case of COVID-19 in Latin America

Singh L, Bode L, Budak C, Kawintiranon K, Padden C, Vraga E (2020) Understanding high- and low-quality URL Sharing on COVID-19 Twitter streams. J Comput Soc Sci 3(2):343-366

Smallman S (2015) Whom do you trust? Doubt and conspiracy theories in the 2009 influenza pandemic. J Int Global Stud 6(2):1-24

Soares I (2020) Bolsonaro sobre vacina de covid: "Não é daquele país não, tá? É de Oxford"

Tambuscio T, Ruffo G (2019) Fact-checking strategies to limit urban legends spreading in a segregated society. Appl Netw Sci 4(1):116

Tambuscio M, Oliveira DFM, Ciampaglia GL, Giancarlo R (2018) Network segregation in a model of misinformation and fact-checking. J Comput Soc Sci 1(2):261-275

Tandoc EC (2019) The facts of fake news: a research review. Sociol Compass 13(9):e12724
Vermeer S, Trilling D (2020) Toward a better understanding of news user journeys: a Markov Chain approach. J Stud 21(7):879-894

Vermeer S, Trilling D, Kruikemeier S, de Vreese C (2020) Online news user journeys: the role of social media, news websites, and topics. Digital J. 8(9):1114-1141

Viner K (2016) How technology disrupted the truth. The Guardian. https://www.theguardian.com/media/2016/jul/12/how-technologydisrupted-the-truth. Accessed: 29 Oct 2020

Vraga EK, Melissa T, Leticia B (2020) Empowering users to respond to misinformation about covid-19. Media Commun 8(2):475-479

Wagner K (2020) Facebook, Twitter, YouTube Remove Posts From Bolsonaro. Bloomberg. https://www.bloomberg.com/news/artic les/2020-03-31/facebook-twitter-pull-misleading-posts-from-brazil-s-bolsonaro. Accessed 29 Oct 2020

Walter N, Cohen J, Lance HR, Morag Y (2020) Fact-checking: a meta-analysis of what works and for whom. Polit Commun 37(3):350-375

WHO (2020) UN tackles 'infodemic' of misinformation and cybercrime in COVID-19 crisis. World Health Organization - United Nations. https://www.un.org/en/un-coronavirus-communicat ions-team/un-tackling- 'infodemic'-misinformation-and-cyber crime-covid-19. Accessed 29 May 2020

Wood T, Porter E (2017) The elusive backfire effect: mass attitudes' steadfast factual adherence. SSRN Electron J 6

Yuan X, Schuchard RJ, Crooks AT (2019) Examining emergent communities and social bots within the polarized online vaccination debate in Twitter. Social Media Soc 5(3):1-12

Zeng J, Zhang S, Wu C, Xie J (2007) Predictive model for internet public opinion. In: Proceedings-fourth international conference on fuzzy systems and knowledge discovery, FSKD 3:7-11

Zhao WX, Jiang J, Weng J, He J, Lim EP, Yan H, Li X (2011) Comparing twitter and traditional media using topic models. In: Lecture notes in computer science (including subseries Lecture notes in artificial intelligence and lecture notes in bioinformatics), volume 6611 LNCS. Springer, Berlin, pp 338-349

Zhao L, Qiu X, Wang X, Wang J (2013) Rumor spreading model considering forgetting and remembering mechanisms in inhomogeneous networks. Physica A 392(4):987-994

Publisher's Note Springer Nature remains neutral with regard to jurisdictional claims in published maps and institutional affiliations. 